\title{
Evaluation of a candida antigen detection method (Cand-Tec): Experience from a university teaching hospital
}

\author{
TODD J ANDERSON, MD, FRCPC, HEATHER E BRYANT, MD, CCFP, PHD, FRCPC, \\ DEIRDRE L CHURCH, MD, PHD, FRCPC
}

\begin{abstract}
TJ ANDerson, HE Bryant, DL Church. Evaluation of a candida antigen detection method (Cand-Tec): Experience from a university teaching hospital. Can J Infect Dis 1992;3(4):167-172. The usefulness of a rapid latex agglutination method for the detection of candida antigen (Cand-Tec; Ramco Laboratories, Texas) was retrospectively assessed in a university teaching hospital over a one year period. Patients were enrolled when the managing physician requested Cand-Tec testing for confirmation of possible invasive candidal infection. The majority of patients were critically ill; $56 \%$ were in the intensive care unit, and 30\% subsequently died. Analyses were available from 79 patients and 125 samples. Thirty-three patients were diagnosed as having either definite invasive candidiasis or a high probability of infection based upon clinical, microbiological and tissue criteria. The sensitivity and specificity of candida antigen detection was determined for doubling titres $\geq 1: 4$ to $\geq 1: 16$. If a titre of $\geq 1: 4$ was used as the diagnostic cut-off level for definite candidal infection, overall sensitivity and specificity were $77 \%$ and $69 \%$, respectively, while the positive predictive value was $48 \%$, and the negative predictive value $89 \%$. When patients with a high probability of invasive candidal infection were included in analyses for a cut-off titre of $\geq 1: 4$, overall sensitivity and specificity were $70 \%$ and $69 \%$, respectively, while the positive predictive value was $68 \%$, and the negative predictive value $71 \%$. The usefulness of the Cand-Tec test was not improved further for any subgroup of patients (including those in the intensive care unit), nor by following serial titres in individual patients. In this experience, the Cand-Tec test did not add enough information to include definitively or exclude invasive candidiasis in this high risk general patient population.
\end{abstract}

\section{Key Words: Cand-Tec, Candida antigen detection, Candidiasis, Candidemia}

\section{Évaluation d'une méthode de détection de l'antigène spécifique de candida (Cand-Tec): Expérience d'un centre hospitalier universitaire}

\begin{abstract}
RÉSUMÉ: On a procédé à l'étude rétrospective d'un test rapide d'agglutination au latex servant à la détection de l'antigène spécifique de candida dans un centre hospitalier universitaire, sur une période d'un an. Les patients ont été retenus chaque fois que le médecin traitant a demandé qu'on procède à un test Cand-Tec pour confirmer une candidose systémique possible. La majorité des patients étaient gravement malades; $56 \%$ étaient hospitalisés au Service de soins intensifs et $30 \%$ sont décédés. Les analyses ont été obtenues pour 79 patients et d'après 125 échantillons. Un diagnostic ferme de candidose systémique ou de probabilité élevée d'infection fondée sur des critères cliniques, microbiologiques et sur des signes histologiques d'invasion tissulaire a été posé chez 33 patients. La sensibilité et la spécificité de la détection a été déterminée lorsqu'elles doublaient les titres d'une valeur supérieure ou égale à 1:4, à une valeur supérieure ou égale
\end{abstract}

Departments of Microbiology and Infectious Diseases, Medicine, and Community Health Sciences, Foothills Hospital; and the University of Calgary, Calgary. Alberta

Correspondence and reprints: Dr Deirdre L Church, c/o 12th floor Microbiology Laboratory, Foothills Hospital, 1403 - 29th Street NW. Calgary, Alberta T2N 2T9. Telephone (403) 670-2584

This paper was presented at the 29th Interscience Conference on Antimicrobial Agents and Chemotherapy, Houston, Texas, USA, September 1989.

Received for publication January 2, 1991. Accepted July 10, 1991 
à 1:16. Quand un titre supérieur ou égal à 1:4 servait de seuil compatible avec le ferme diagnostic de candidose, la sensibilité et spécificité globales atteignaient $77 \%$ et $69 \%$ respectivement, tandis que la valeur de prévision d'un test positif était de $48 \%$ et celle d'un test négatif, de $89 \%$. Quand les cas de probabilité élevée d'infection ont été inclus dans l'analyse avec un titre seuil supérieur ou égal à 1:4, la sensibilité et spécificité globales étaient de $70 \%$ et $69 \%$ respectivement, tandis que le pourcentage de prévision d’un test positif atteignait $68 \%$ et celui d’un test négatif, $71 \%$. L'utilité du test Cand-Tec ne s'est améliorée pour aucun des sous-groupes de patients (ni pour ceux qui recevaient des soins intensifs ni en suivant des titres sériés chez des patients individuels). Dans la présente expérience, le test Cand-Tec n’a pas fourni assez de données supplémentaires pour permettre d'inclure ou d'exclure un diagnostic formel de candidose systémique dans cette population générale de patients à haut risque.

S STEMIC CANDIDIASIS REMAINS A SIGNIFICANT CAUSE OF hospital mortality particularly among high risk groups. It is prevalent in intensive care unit patients and in patients with various types of immunosuppression $(1,2)$. Deep-seated candidal infections are difficult to diagnose accurately, resulting in significant delays in initiation of appropriate antifungal therapy. Definitive diagnosis based upon a 'gold standard' definition of invasive candidiasis can only be made by histopathological demonstration of Candida species invasion of tissue(s) - seldom achieved in critically ill patients. Instead, patients are most often started on empiric antifungal treatment when a probable diagnosis of invasive candidal infection is made. Most often, patients suspected of having invasive infection have significant clinical risk factors for fungal infection, and Candida species is subsequently isolated from one or more important body sites, eg, blood, urine or sputum (3).

The difficulties in making a definitive diagnosis of invasive candidal infection have encouraged the development and evaluation of immunological diagnostic methods (4-6). The insensitivity of antibody detection methods in critically ill, immunocompromised patients has led to the development of serodiagnostic tests for circulating candida antigens. The only commercially available Candida species detection system (Cand-Tec; Ramco Laboratories, Texas) uses uniformsized latex particles coated with an anticandida antibody to detect the presence of candida antigens in the serum of patients by an agglutination reaction (7). However, the antigen detected by this system has not been purified and characterized, so it is not certain what is being detected by the Cand-Tec test.

At present, the clinical usefulness of the Cand-Tec test remains controversial. Several studies have reported widely varying values for the sensitivity and specificity of the test in differentiating between Candida species colonization and infection. Several studies have reported the Cand-Tec test to be useful for the detection of invasive candidiasis (8-12). However, other studies have not confirmed these results (13-16). Most previous studies have either focused on highly selected patient populations or small numbers of patients in whom a definite diagnosis of invasive candidiasis had already been made by the 'gold standard' techniques of positive fungal cultures for Candida species from deep tissue biopsies, or histopathological evidence of fungal infection from post mortem tissue examination. Therefore, it was of interest to evaluate the Cand-Tec test retrospectively in a general hospital population at risk for invasive candidal infection. The main purpose of this study was to decide if the test should be offered by the clinical microbiology laboratory and, if so, to establish clear guidelines for its use in diagnosing invasive candidiasis.

\section{MATERIALS AND METHODS}

Patient population: Foothills Hospital is a large university teaching institution providing a wide range of tertiary care services including intensive care (traumasurgical, coronary, neurological and burn units) to patients throughout southern Alberta. Over a one year period, the candida antigen detection system (CandTec) was retrospectively evaluated in this general patient population. Prior to the introduction of the Cand-Tec test by the clinical microbiology laboratory, an educational memorandum was circulated to all physicians at the hospital outlining the principles of the test and its usefulness based upon previous studies.

During a one year study period, Cand-Tec tests were ordered mainly by specialist physicians providing primary or intensive care to patients with risk factors for developing invasive candidal infection. The infectious diseases service clarified the reasons for Cand-Tec testing in all cases in which the clinical information provided to the laboratory was inadequate or unclear. No restrictions were initially placed on the number of Cand-Tec tests that could be done per patient. However, three months after introduction, because of cost constraints and the practice of some physicians in ordering daily tests, the laboratory restricted the frequency of testing to no more than two Cand-Tec determinations per week per patient. A cut-off titre of $\geq 1: 4$ was considered to be significant and possibly diagnos tic of invasive candidiasis, based upon previously re ported study results (7). All microbiology reports read: "Cand-Tec titre $\geq 1: 14$ which may be diagnostic of invasive candidiasis. Please correlate with clinical picture.

All patients who had Cand-Tec tests also had extensive surveillance cultures for yeast taken from several peripheral sites including throat, blood, sputum, stool and urine. 
Data collection: All eligible patients in whom the CandTec test was done on one or more occasions were retrospectively reviewed. Between October 1, 1987 and October 1, 1988 a total of 82 patients (43 females, 39 males) and 151 individual samples were evaluated. The final analyses included 79 patients (43 females, 36 males) and 125 individual samples. Three patients with rheumatoid arthritis were excluded because rheumatoid factor may interfere with the Cand-Tec test. Also, Cand-Tec tests done on patients after amphotericin B treatment was started were not included for analysis.

Chart reviews recorded the following information: patient's age, sex, length of stay in hospital, diagnoses (including underlying immunosuppressive factors), recent surgery, total parenteral nutrition, admission to the intensive care unit, antibiotic therapy, results from fungal surveillance cultures including throat, sputum, and serial blood, urine and stool cultures, biochemical tests including peak serum creatinine levels, and all available biopsy and/or autopsy results.

Patients were classified into four groups based upon the following clinical and laboratory criteria. 'Definite infection' - patients with definite evidence of disseminated candida infection demonstrated by histological evidence of tissue invasion and/or positive tissue fungal cultures and/or positive blood cultures on more than one occasion. 'Probable infection' - patients with multiple clinical risk factors for invasive candidiasis (broad spectrum antibiotic use at the time of test and/or within two weeks preceding test, recent abdominal surgery, total parenteral nutrition, immunosuppression from any cause, prolonged hospital stay, or admission to an intensive care unit), as well as two or more significant peripheral sites culture positive for Candida species (eg, sputum, wound), and/or persistent candiduria (positive urine fungal culture for Candida species on more than one occasion). 'Colonization' - patients with less than two of the clinical risk factors for invasive candidiasis outlined above ('probable infection' group) and a positive fungal culture from a single peripheral site other than blood. 'No infection' patients with no clinical or fungal culture evidence of invasive candidal infection.

Statistical analysis: All analyses were done using the highest titres for each patient. The sensitivity, specificity, and positive and negative predictive values for diagnosis of invasive candidiasis were calculated using cut-off Cand-Tec titres of $\geq 1: 4, \geq 1: 8$ and $\geq 1: 16$. All patients in the 'definite infection' group were included as disease positive. Results from patients in the 'no infection' group were used as negative disease. The sensitivity, specificity, and positive and negative predictive values to support a suspected diagnosis of invasive candidiasis were calculated in a similar manner, except that patients in the 'probable infection' group were also included as having positive disease.

Microbiological methods: Culture of blood specimens was performed using a standard broth system (Bactec; Becton-Dickinson). All blood cultures requesting fungal isolation were plated to primary fungal media including inhibitory mold and chocolate agars. All blood fungal cultures were kept and analyzed for 21 days. Routine bacteriological or fungal cultures which isolated yeast(s) were identified as $C$ albicans versus other Candida species by demonstration of germ tube production, and by assimilation profiles with the API-20C (API Analytab Products, New York).

Candida antigen detection: A commercially available latex agglutination system (Cand-Tec; Ramco Laboratories, Texas) was used to detect candida antigen. Samples were tested as previously described (7). If agglutination occurred at $\mathrm{a} \geq 1: 2$ dilution, then serial twofold dilutions (up to $\geq 1: 64$ ) were done. The endpoint was the highest dilution at which agglutination occurred. Rheumatoid factor was assayed in all patients with a positive titre.

\section{RESULTS}

Of the 79 patients, 13 had definite invasive candidiasis and were included in the 'definite infection' group, 20 had probable infection, and 46 were only colonized with Candida species or had no evidence of infection (Table 1). The mean age of the study population was 52 years (range 0 to 81 ) and the mean length of stay in hospital was 47 days (range one to 200). The majority of patients studied were critically ill: 57\% were situated in the intensive care unit, and 30\% subsequently died (Table 1). The highest mortality rate occurred in the group with definite infection $(44.5 \%)$. Patients in each diagnostic group had prolonged intensive care unit stays, indicating the overall severity of illness in the present study population. Not surprisingly, patients in all diagnostic categories admitted to the intensive care unit had much longer hospital stays than those who did not require this type of care.

Table 1 also gives patient profiles for other associated variables which are known to increase the risk of invasive candidiasis. The use of broad spectrum antibiotics and central total parenteral nutrition were common in the 'definite' and 'probable infection' groups. Up to one-third of patients in each diagnostic patient group were immunocompromised for various reasons (Table 1). Most patients in the 'definite infection' group had renal insufficiency (62\%), compared with $40 \%$ of patients with probable infection and only $13 \%$ of patients in the 'colonization/no infection' groups. Some patients with positive Cand-Tec titres had normal renal function at the time of their tests, while others had mild to severe renal insufficiency.

Amphotericin B treatment was common in patients with definite or probable invasive candidal infection (Table 1). Most fungal cultures from patients in all groups isolated $C$ albicans. Candida tropicalis was isolated from a protected brush specimen from one 
TABLE 1

Patient descriptions and outcomes versus candidal infection status

\begin{tabular}{|c|c|c|c|}
\hline \multirow[b]{2}{*}{ Parameter } & \multicolumn{3}{|c|}{ Candidal infection status } \\
\hline & Definite infection $(n=13)$ & Probable infection $(n=20)$ & Colonization/no infection $(n=46)$ \\
\hline Mean age (years) & $60 \pm 19$ & $54 \pm 21$ & $50 \pm 20$ \\
\hline Mean length of stay (days) & $55 \pm 50$ & $76 \pm 57$ & $33 \pm 29$ \\
\hline \multicolumn{4}{|l|}{ Intensive care unit stay } \\
\hline Number of patients & $12 / 13(92 \%)$ & $14 / 20(70 \%)$ & $14 / 46(30 \%)$ \\
\hline Mean length of stay (days) & $58 \pm 51$ & $76 \pm 57$ & $53 \pm 37$ \\
\hline Immunocompromised & $2 / 13(15 \%)^{*}$ & $3 / 20(15 \%)^{\dagger}$ & $13 / 46(28 \%)^{\ddagger}$ \\
\hline Treatment with amphotericin B & $9 / 13(69 \%)$ & $9 / 20(45 \%)$ & $3 / 46(7 \%)$ \\
\hline Renal dysfunction ${ }^{\S}$ & $8 / 13(62 \%)$ & $8 / 20(40 \%)$ & $6 / 46(13 \%)$ \\
\hline Patients who died & $6 / 13(46 \%)$ & $7 / 20(35 \%)$ & $11 / 46(24 \%)$ \\
\hline Number autopsied & $2 / 6(33 \%)$ & $0 / 7(0 \%)$ & $3 / 11(27 \%)$ \\
\hline
\end{tabular}

TABLE 2

Characteristics of Cand-Tec testing versus candidal infection status

\begin{tabular}{|c|c|c|c|}
\hline Cand-Tec testing profile & Definite infection $(n=13)$ & $\begin{array}{l}\text { Candidal infection status } \\
\text { Probable infection }(n=20)\end{array}$ & Colonization/no infection $(n=46)$ \\
\hline \multicolumn{4}{|l|}{ Number done per patient: } \\
\hline Single & $3 / 13(23 \%)$ & $8 / 20(40 \%)$ & $36 / 46(78 \%)$ \\
\hline Multiple & $10 / 13(77 \%)$ & $12 / 20(60 \%)$ & $10 / 46(22 \%)$ \\
\hline \multicolumn{4}{|l|}{ Timing of the test relative to: } \\
\hline Positive cultures/diagnosis & $5 \pm 3$ days & $12 \pm 13$ days & ND \\
\hline Autopsy & $6 \pm 2$ days & None & ND \\
\hline \multicolumn{4}{|l|}{ Highest test titre per patient: } \\
\hline Negative & $0(0 \%)$ & $2 / 20(10 \%)$ & $18 / 46(39 \%)$ \\
\hline $1: 2$ & $3 / 13(23 \%)$ & $5 / 20(25 \%)$ & $10 / 46(22 \%)$ \\
\hline $1: 4$ & $2 / 13(15 \%)$ & $2 / 20(10 \%)$ & $10 / 46(22 \%)$ \\
\hline $1: 8$ & $5 / 13(39 \%)$ & $7 / 20(35 \%)$ & $6 / 46(13 \%)$ \\
\hline $1: 16$ & $2 / 13(15 \%)$ & $1 / 20(5 \%)$ & $2 / 46(4 \%)$ \\
\hline $1: 32$ & $1 / 13(8 \%)$ & $3 / 20(20 \%)$ & $0(0 \%)$ \\
\hline
\end{tabular}

ND Not determined

patient. Patients with fungemia who had yeast isolated on more than one occasion included one patient with $C$ albicans, another with $C$ tropicalis, and two with $C a n-$ dida parapsilosis (one of whom subsequently had $C$ parapsilosis isolated from a Swan Ganz tip). In the 'probable infection' group, three patients had $C$ tropicalis cultured from either sputum (three), urine (one), wounds (two) or bronchial wash specimens (one). Patients who were infected with Candida species other than $C$ albicans demonstrated significant titres in the Cand-Tec test.

Table 2 illustrates the characteristics of Cand-Tec testing versus the patient's designated candidal infection status. Most patients in the 'definite infection' group had multiple Cand-Tec titres done. Despite tissue culture evidence of invasive candidal infection, most patients did not demonstrate rising Cand-Tec titres prior to the initiation of therapy. Most patients $(77 \%)$ in the definite infection group had Cand-Tec titres $\geq 1: 4$. On average, Cand-Tec tests were done five days prior to definitive diagnosis of fungal infection and initiation of amphotericin B therapy. Of the six patients who died in the definite infection group, three had post mortem examinations (Table 1). One patient had a Cand-Tec titre of $\geq 1: 32$ five days prior to death and was confirmed at autopsy to have invasive candidiasis. The two other autopsied patients had been on amphotericin $\mathrm{B}$ prior to death and showed no evidence of invasive candidiasis at post mortem examination. Both patients had been fungemic prior to death - the patient with $C$ albicans infection had serial Cand-Tec titres of $\geq 1: 2$ (five and nine days prior to death), while the patient with $C$ parapsilosis infection had serial Cand-Tec titres of $\geq 1: 8$ and $\geq 1: 16$. 
Most patients in the 'probable infection' group also had multiple Cand-Tec titres done (Table 2). The highest Cand-Tec titre for most patients in this group was $\geq 1: 4(70 \%)$. On average, Cand-Tec tests were done 12 days after diagnosis of fungal infection by extensive peripheral site cultures. As shown by the large standard deviation (Table 2), Cand-Tec tests were done in several patients several weeks after infection had been confirmed by peripheral body site fungal cultures.

Most patients in the 'colonization' and 'no infection' groups had only single Cand-Tec titres done (Table 2). Most of the time, Cand-Tec tests were ordered randomly in these patient groups, and testing bore no relationship to cultures. The highest Cand-Tec titres in these patients were often $\geq 1: 4(51 \%)$, and the majority had titres $\leq 1: 8(83 \%)$.

Table 3 outlines the ability of the Cand-Tec test to diagnose invasive candidiasis in the definite infection group for various cut-off titres between $\geq 1: 4$ and $\geq 1: 16$. The Cand-Tec test was neither adequately sensitive or specific at a cut-off titre of $\geq 1: 4$. Test sensitivity, specificity, and positive and negative predictive values were $77 \%, 61 \%, 36 \%$ and $90 \%$, respectively. The specificity could be improved by increasing the cut-off titre to $\geq 1: 8(78 \%)$ or $\geq 1: 16(96 \%)$. Sensitivity of the test substantially decreased as the cut-off titre was moved up to $\geq 1: 16$ (30\%). Similar changes occurred in the positive and negative predictive values for the test as the cut-off titre was increased.

Table 4 outlines the ability of the Cand-Tec test to support a clinical diagnosis of probable invasive candidal infection for various cut-off titres between $\geq 1: 4$ and $\geq 1: 16$. Including patients in the 'probable infection' group in the analyses did not appreciably change the ability of the Cand-Tec tests to diagnose invasive candidiasis accurately at a cut-off titre of $\geq 1: 4$. Test sensitivity, specificity, and positive and negative predictive values were $70 \%, 61 \%, 56 \%$ and $74 \%$, respectively. Again, specificity could be improved by increasing the cut-off titre to $\geq 1: 8(78 \%)$ or $\geq 1: 16(96 \%)$. However, sensitivity of the test substantially decreased as the cut-off titre was moved up to $\geq 1: 16$ (21\%).

Increasing the cut-off titre above $\geq 1: 4$ did not significantly alter the positive and negative predictive values of the test.

Restricting the analyses further to patients who were critically ill and in the intensive care unit did not enhance the diagnostic ability of this test considered alone or in combination with culture data in definite exclusion of candidal infection.

\section{DISCUSSION}

Invasive candidiasis remains a serious and difficult infection to diagnose and treat in the authors' institution, particularly in critically ill patients. Over a one year period in a general hospital setting, the authors evaluated 33 patients with a definite or probable diag-
TABLE 3

Analysis of the Cand-Tec test's ability to diagnose invasive candidiasis in high risk patients*

\begin{tabular}{lccc}
\hline $\begin{array}{l}\text { Test } \\
\text { performance }\end{array}$ & \multicolumn{3}{c}{ Candida antigen threshold titre } \\
(Cand-Tec) \\
Sensitivity (\%) & $10 / 13(77 \%)$ & $8 / 13(62 \%)$ & $3 / 10(30 \%)$ \\
Specificity (\%) & $24 / 35(69 \%)$ & $29 / 35(83 \%)$ & $33 / 35(94 \%)$ \\
PPV (\%) & $10 / 21(48 \%)$ & $8 / 14(57 \%)$ & $3 / 5(60 \%)$ \\
NPV (\%) & $24 / 27(89 \%)$ & $29 / 34(85 \%)$ & $33 / 43(77 \%)$ \\
\hline
\end{tabular}

*Only patients within the definite infection group are included in the positive disease/positive test category for these analyses. ${ }^{\dagger}$ Analyses were done using the highest titre recorded for each patient. NPV Negative predictive value; PPV Positive predictive value

\section{TABLE 4}

Analysis of the Cand-Tec test's ability to support a suspected diagnosis of invasive candidiasis in high risk patients*

\begin{tabular}{lccc}
\hline $\begin{array}{l}\text { Test } \\
\text { performance }\end{array}$ & \multicolumn{3}{c}{ Candida antigen threshold titre } \\
(Cand-Tec) \\
Sensitivity (\%) & $23 / 33(70 \%)$ & $19 / 33(58 \%)$ & $7 / 33(21 \%)$ \\
Specificity (\%) & $24 / 35(69 \%)$ & $29 / 35(83 \%)$ & $33 / 35(94 \%)$ \\
PPV (\%) & $23 / 34(68 \%)$ & $19 / 25(76 \%)$ & $7 / 9(78 \%)$ \\
NPV (\%) & $24 / 34(71 \%)$ & $29 / 43(64 \%)$ & $33 / 59(63 \%)$ \\
\hline
\end{tabular}

*All patients within the definite and probable infection groups are included in the positive disease/positive test category for these analyses. t Analyses were done using the highest titre recorded for each patient. NPV Negative predictive value; PPV Positive predictive value

nosis of invasive candidal infection, and 46 others in whom the diagnosis was considered. Analysis using only the 'definite infection' group (Tables 3) as well as both the 'definite' and 'probable infection' groups (Table 4) demonstrated that the Cand-Tec test was less than optimal in helping to confirm or rule out a diagnosis of invasive candidiasis. Not surprisingly, there was a trade-off between the level of sensitivity and specificity for the test depending upon the Cand-Tec titre used as the cut-off for diagnosis of invasive infection. Even when the 'probable infection' group patients were excluded from analysis (Table 3), the maximal sensitivity $(77 \%)$ occurred at a cut-off titre of $\geq 1: 4$ when the specificity of the test was only $69 \%$. Similarly, positive and negative predictive values for the test were poor regardless of the cut-off Cand-Tec titre used (Tables $3,4)$. The variation between Tables 3 and 4 in the positive and negative predictive values observed for different cut-off levels occurred mainly because the prevalence of disease differed in the populations being considered in the analyses. To carry this further, if the test was to be used in a less selected population with lower disease prevalence than the present one, the positive predictive values would fall even further.

The present results are comparable with the larger study of Cabezubo et al (12) who also demonstrated poor diagnostic ability of the Cand-Tec test in a general 
hospital population. However, Cabezubo et al (12) suggested that the determination of serial titres might be helpful in early diagnosis of invasive infection. Although the role of serial titres was not formally evaluated in the present patient population, no predictable trend was found in patients who had multiple titres done. Despite no treatment, several patients demonstrated marked fluctuations in their titres from one determination to the next, which further confused a difficult clinical situation.

Other published data regarding the usefulness of the Cand-Tec test are contradictory, likely because highly pre-selected patient populations were studied. The initial study of Gentry et al (7) reported a sensitivity of $91 \%$ in 33 patients with confirmed invasive candidiasis (positive blood or organ tissue culture for $C$ albicans plus fever). In a controlled follow-up study evaluating the Cand-Tec test in other high risk patient populations, Price and Gentry (9) demonstrated variable sensitivity but a universally high specificity (97\%) for all patient groups using a cut-off titre of $\geq 1: 4$. Subsequent studies by other groups have shown the Cand-Tec test to have variable but not nearly as high sensitivity and specificity in highly selected patient populations $(8,10,11,14-16)$.

ACKNOWLEDGEMENTS: We acknowledge the technical staff of the Foothills Hospital microbiology laboratory for their assistance with this study.

\section{REFERENCES}

1. Mygrowitz RL, Pazin GJ, Allen CM. Disseminated candidiasis. Changes in incidence, underlying diseases, and pathology. Am J Clin Pathol 1977;68:29-38.

2. Meunier-Carpentier F, Kiehn JE, Armstrong D. Fungemia in the immunocompromised host. Changing patterns, antigenemia, high mortality. Am J Med 1981;71:363-70.

3. Edwards JE Jr. Candida species. In: Mandell GL, Douglas RG Jr, Bennett JE, eds. Principles and Practice of Infectious Diseases. New York: Churchill Livingstone, 1990:1943-58.

4. Hopwood V, Warnock DW. New developments in the diagnosis of opportunistic fungal infection. Eur J Clin Microbiol 1986:5:379-88.

5. de Repentigny L, Reiss E. Current trends in immunodiagnosis of candidiasis and aspergillosis. Rev Infect Dis 1984;6:301-12.

6. Bennett JE. Rapid diagnosis of candidiasis and aspergilloses. Rev Infect Dis 1987;9:398-402.

7. Gentry LO, Wilkinson ID, Lea AS, Price MF. Latex agglutination test for detection of candida antigen in patients with disseminated disease. Eur J Clin Microbiol 1983;2:122-8.

8. Burnie JP, Williams JD. Evaluation of the Ramco latex
The present study and others (14-16) demonstrate that the Cand-Tec test does not appreciably enhance physicians' ability to diagnose invasive candidal infection beyond standard histopathological and microbiological methods. In addition, the test did not demonstrate sufficient specificity or negative predictive value in the present patient population to rule out absolutely invasive infection in patients colonized with Candida species. Therefore, it is not likely that set clinical and laboratory criteria would enhance the performance of the Cand-Tec test in a general hospital setting. In addition, false positive Cand-Tec results without careful clinical and laboratory follow-up of the patient may lead to the inappropriate initiation of potentially toxic antifungal therapy. During the study, several patients with persistently elevated Cand-Tec titres and otherwise limited evidence of invasive fungal infection were empirically treated with prolonged courses of amphotericin B.

At the authors' institution, the diagnosis of invasive candidiasis in high risk patients continues to rest with the astute clinician. The Cand-Tec test is no longer performed on a routine basis by the hospital's clinical microbiology laboratory.

agglutination test in the early diagnosis of systemic candidiasis. Eur J Clin Microbiol 1985;4:98-101.

9. Price MF, Gentry LO. Incidence and significance of candida antigen in low risk and high risk patient populations. Eur J Clin Microbiol 1986;5:416-9.

10. Fung JC, Donta ST, Tilton RC. Candida detection system (Cand-Tec) to differentiate between Candida albicans colonization and disease. J Clin Microbiol 1986;24:542-7.

11. DeLozier JB III, Stratton CW, Potts JR III. Rapid diagnosis of candida sepsis in surgical patients. Am Surg 1987;53:600-2.

12. Cabezubo I, Pfaller M, Gerarden T, et al. Value of the Cand-Tec candida antigen assay in the diagnosis and therapy of systemic candidiasis in high-risk patients. Eur J Clin Microbiol 1989;8:770-7.

13. Piens M-A, Guyotat D, Archimbaud E, et al. Evaluation of a candida antigen detection test (Cand-Tec) in the diagnosis of deep candidiasis in neutropenic patients. Eur J Clin Oncol 1988; 124:1655-9.

14. Bailey JW, Sada E, Brass C, Bennett JE. Diagnosis of systemic candidiasis by latex agglutination for serum antigen. J Clin Microbiol 1985;21:749-52.

15. Kahn FW, Jones JM. Latex agglutination tests for detection of candida antigen in sera of patients with invasive candidiasis. J Infect Dis 1986;153:579-85.

16. Ness MJ, Vaughn WP, Woods GL. Candida antigen latex test for detection of invasive candidiasis in immunocompromised patients. J Infect Dis 1989; 159:495-502. 


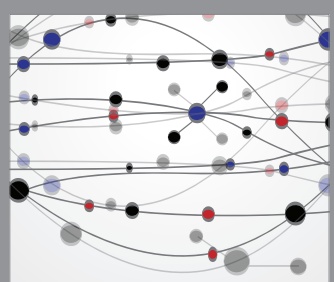

The Scientific World Journal
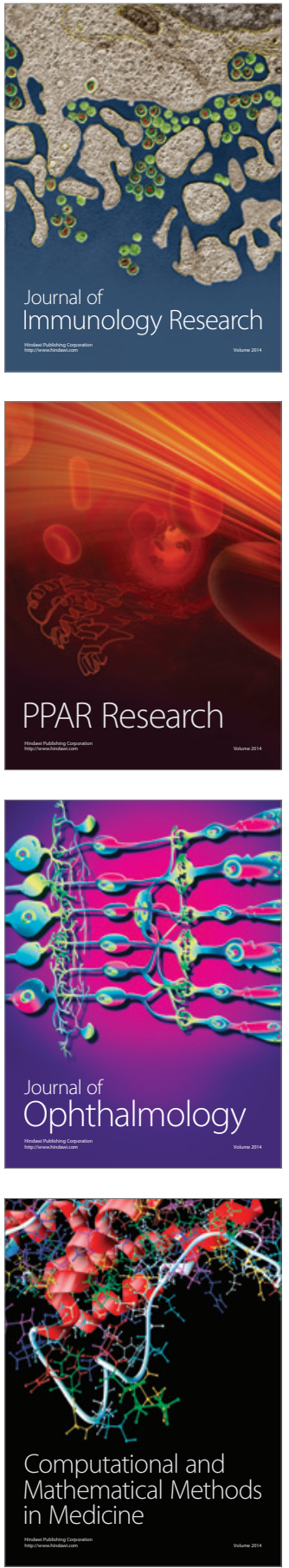

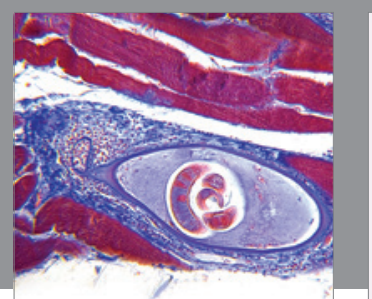

Gastroenterology Research and Practice

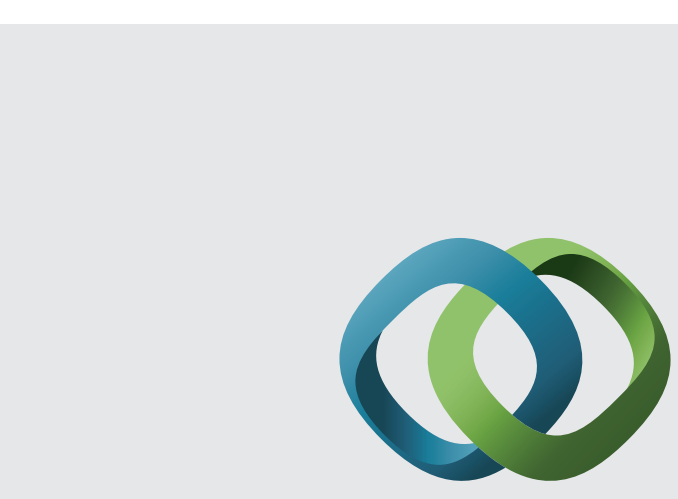

\section{Hindawi}

Submit your manuscripts at

http://www.hindawi.com
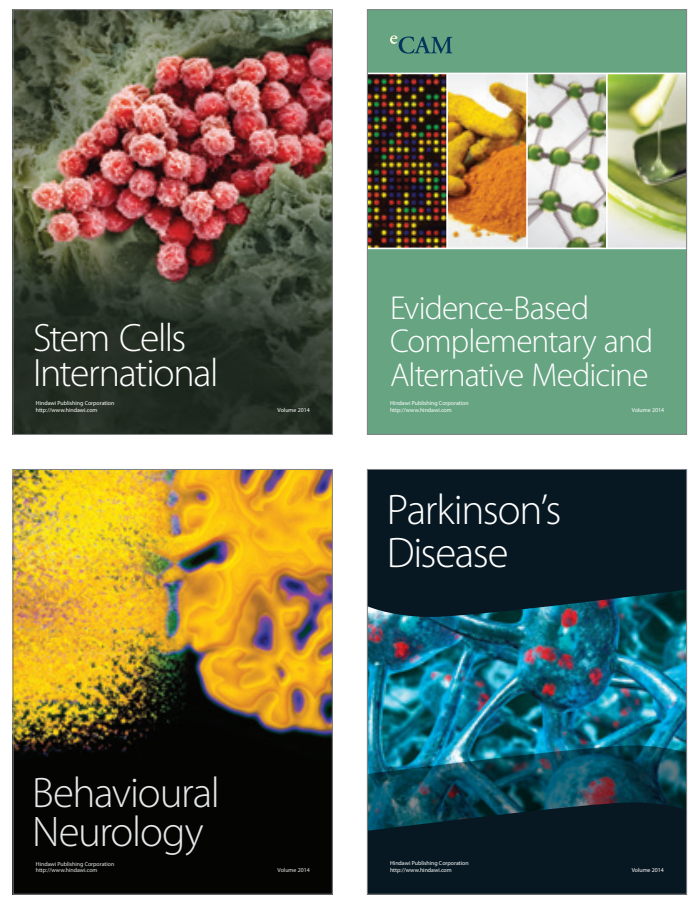
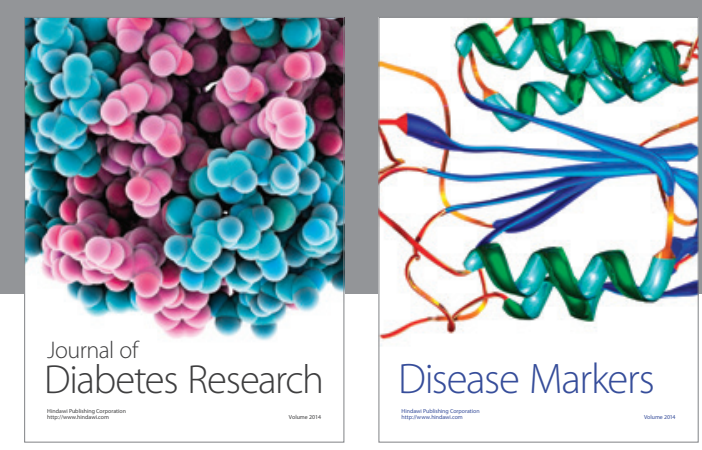

Disease Markers
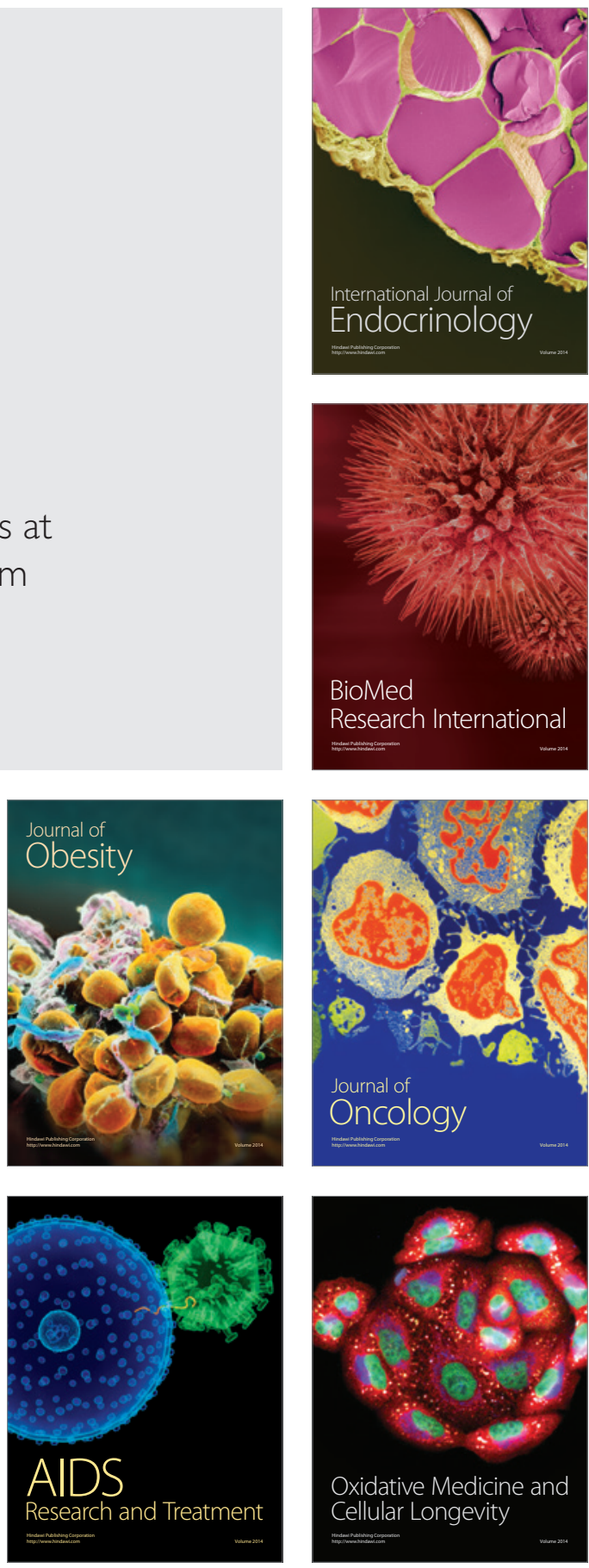